\title{
Molecular characterization of Echinococcus granulosus isolates from Bulgarian human cystic echinococcosis patients
}

\author{
Irina Marinova $^{1,2} \cdot$ Markus Spiliotis $^{1} \cdot$ Junhua Wang $^{1} \cdot$ Marin Muhtarov $^{2,3}$. \\ Ilias Chaligiannis ${ }^{4} \cdot$ Smaro Sotiraki $^{4}$ - Iskra Rainova ${ }^{2} \cdot$ Bruno Gottstein $^{1}$ (D) \\ Ghalia Boubaker ${ }^{1,5}$
}

Received: 29 November 2016 / Accepted: 16 January 2017 /Published online: 21 January 2017

(C) Springer-Verlag Berlin Heidelberg 2017

\begin{abstract}
Although cystic echinococcosis (CE) is highly endemic in Bulgaria, there is still scarce information about species and/or genotypes of the Echinococcus granulosus complex that infect humans. Our study tackled the genetic diversity of $E$. granulosus complex in a cohort of 30 Bulgarian $\mathrm{CE}$ patients. Ten animal E. granulosus isolates from neighboring Greece were additionally included. Specimens were comparatively analyzed for partial sequences of five mitochondrial (mt) (cox I, nad I, rrnS, rrnL, and atp6) and three nuclear (nc) genes (act II, hbx 2, and ef- $1 \alpha$ ) using a PCRsequencing approach. All 30 Bulgarian isolates were identified as E. granulosus sensu stricto (s.s.) and were showing identical sequences for each of the three examined partial nc gene markers. Based upon concatenated sequences from partial mtDNA markers, we detected 10 haplotypes: 6 haplotypes (H1-H6) clustering with E. granulosus s.s. (G1) and 4 haplotypes (H9-H13) grouping with E. granulosus s.s. (G3), with $\mathrm{H} 1$ and $\mathrm{H} 10$ being the most frequent in Bulgarian patients. The haplotypes H1, H4, and H11 were also present in Greek
\end{abstract}

Bruno Gottstein

bruno.gottstein@vetsuisse.unibe.ch

1 Institute of Parasitology, Vetsuisse Faculty and Faculty of Medicine, University of Bern, 3012 Bern, Switzerland

2 Department of Parasitology and Tropical Medicine, National Center of Infectious and Parasitic Diseases, Sofia, Bulgaria

3 Multi-Profile Hospital for Active Treatment "Kardzhali", Gastroenterology Ward, Kardzhali, Bulgaria

4 Hellenic Agricultural Organisation-Demeter, Veterinary Research Institute, Thessaloniki, Greece

5 Department of Clinical Biology B, Laboratory of Medical and Molecular Parasitology-Mycology (LR12ES08), Faculty of Pharmacy, University of Monastir, Monastir, Tunisia hydatid cyst samples of animal origin. In conclusion, E. granulosus s.s. (G1 and G3 genotypes) is the only causative agent found so far to cause human $\mathrm{CE}$ in Bulgaria. However, further studies including larger sample sizes and other additional geographic regions in Bulgaria will have to be performed to confirm our results.

Keywords Echinococcus spp. PCR · Genotyping · Speciation $\cdot$ Nuclear markers $\cdot$ Mitochondrial markers

\section{Introduction}

Cystic echinococcosis (CE) is a chronic helminthic zoonosis of worldwide distribution. Disease (CE) is caused by the development of larval stages of tapeworms (cestodes) belonging to the genus Echinococcus (family Taeniidae). CE affects a wide variety of livestock species which act as intermediate hosts (IH), while humans actually represent aberrant IH (Eckert et al. 2004). Within the genus Echinococcus, two major species are of medical importance, including $E$. granulosus sensu lato (s.l.) and E. multilocularis that cause $\mathrm{CE}$ and alveolar echinococcosis (AE), respectively (Eckert et al. 2004). In contrast to E. multilocularis (Haag et al. 1997; Snabel et al. 2006), E. granulosus s.l. exhibits a high genotypic diversity with 10 genotypes (G1-G10) that were molecularly distinguished so far, predominantly based on genetic polymorphism of mitochondrial (mt) genes (Bowles et al. 1992a, 1994; Bowles and McManus 1993; Scott et al. 1997; Lavikainen et al. 2003). The taxonomy and relationships among various species of the genus Echinococcus were widely reviewed in recent times, and accordingly, E. granulosus s.l. was regarded as an oversimplified species (Thompson and McManus 2002; Jenkins et al. 2005; Nakao et al. 2007; Hüttner et al. 2008; Saarma et al. 2009; Knapp et al. 2011; Nakao et al. 2013). 
Thus to date, the E. granulosus complex consists of five species: E. granulosus sensu stricto (s.s.) (clustering genotypes $\mathrm{G} 1, \mathrm{G} 2$, and G3), E. equinus (G4), E. ortleppi (G5), E. canadensis (grouping genotypes G6-G8 and G10), and E. felidis (G9) (Thompson and McManus 2002; Jenkins et al. 2005; Nakao et al. 2007; Hüttner et al. 2008; Saarma et al. 2009; Knapp et al. 2011; Nakao et al. 2013). The complex phylogenetic relationships among genotypes of the E. canadensis (G6-G8, G10) cluster were revealed by a discrepancy between nuclear (nc) and mt phylogenies. Consequently, this genetic and ecological complexity of E. canadensis (G6-G8, G10) has led to an open debate about dividing it into two or more species (Thompson et al. 2006; Tompson 2008; Moks et al. 2008; Saarma et al. 2009; Lymbery et al. 2015a, b; Nakao et al. 2015).

E. granulosus s.s. accounts for most of the global burden of CE in humans and livestock (Alvarez et al. 2014), and it harbors the largest and the most diverse number of mtDNA haplotypes, which could be explained by many factors such as a large population size, a natural wide IH spectrum, environmental heterogeneity, and/or a clonal reproduction during the larval stage. In general, reported $\mathrm{mt}$ haplotypes gathered by similarity either around G1 or G3, while G2 seems to be a micro-variant of G1 or often of G3 (Snabel et al. 2009; Alvarez et al. 2014). Nevertheless, because of the unclarity on inter-genotypic genetic distances between genotypes G1, G2, and G3 of the E. granulosus s.s., the genotype terminology has been questioned for its biological and genetic validity (Busi et al. 2007; Snabel et al. 2009; Beato et al. 2010; Nakao et al. 2013; Alvarez et al. 2014). Subsequently, to date, two different systems are used to categorize parasite specimens; researchers refer either directly to the species level: E. granulosus s.s. (with various lineages) (Piccoli et al. 2013; Mutwiri et al. 2013; Boufana et al. 2015; Bakal et al. 2015; Wang et al. 2015) or to genotype (with various haplotypes).

Human CE is considered highly endemic in Bulgaria, with an annual incidence of 5.71 cases per 100,000 inhabitants for the period between 2003 and 2012 (Euro Surveillance team 2013; Rainova et al. 2014; Jordanova et al. 2015). In rural areas of Bulgaria such as Sliven, Yambol, Razgrad, Targovishte etc., prevalence may reach up to 7.5-16 cases per 100,000 inhabitants.

So far, there is limited data on the molecular typing of species and genotyping of the E. granulosus complex circulating in Bulgaria (Breyer et al. 2004; Casulli et al. 2012; Boubaker et al. 2013), and accordingly, only E. granulosus s.s. (G1/G2/G3) was found in humans (Casulli et al. 2012) and animals (Breyer et al. 2004; Casulli et al. 2012; Boubaker et al. 2013). In contrast, E. granulosus s.s (G1) and E. canadensis (G7) were identified in both human and livestock from countries adjacent to Bulgaria, such as Greece (Varcasia et al. 2007), Romania (Bart et al. 2006; Casulli et al. 2012; Piccoli et al. 2013), Turkey (Snabel et al. 2009), and Serbia (Maillard et al. 2009; Bobic et al. 2012). E. canadensis (G7) has been also isolated from Macedonian CE patients (Schneider et al. 2010). Thus, preliminary findings showing a non-existence of E. canadensis (G7) in Bulgarian territory, based upon a restricted number of samples, definitively require further investigations for confirmation or else.

Overall, in the present study, we intended (i) to molecularly identify species and genotypes of the $E$. granulosus complex infecting human Bulgarian CE patients and (ii) to investigate their genetic variation respective to $\mathrm{nc}$ and $\mathrm{mt}$ targets.

In addition, we included Greek E. granulosus isolates with the aim to briefly search for matching haplotypes circulating in this neighboring countries.

\section{Materials and methods}

\section{Ethical statement}

Parasite samples of human origin were derived from an existing collection of Echinococcus DNA of the NRL "Diagnostics of Parasitic Diseases" at the National Centre of Infectious and Parasitic Diseases, Sofia, Bulgaria, designed and approved to be used for basic research studies. Cysts were obtained during the routine diagnostic activities of the NRL. The derived samples used in the present study uniquely contained DNA of parasitic origin; thus, no human DNA was included in this study. The parasite samples were fully anonymized respective to the patients' private data, thus requiring no further ethical consideration.

In this study, we also included 10 E. granulosus samples originating from Greek animal cysts that were collected as a part of the governmental meat inspection program of public slaughterhouses. Samples were obtained from the Veterinary Research Institute Hellenic Agricultural Organization-Demeter (former NAGREF), NAGREF Campus, Thermi, Thessaloniki, Greece (Chaligiannis et al. 2015). All protoscoleces and/or cyst walls (germinal and laminar layer) collected were preserved in 70\% ethanol and stored at $-20{ }^{\circ} \mathrm{C}$ for a later parasitological and molecular processing and identification.

\section{Bulgarian human CE patients}

Thirty CE patients (20 females and 10 males) originating from different regions of Bulgaria were included in this study. Cyst collection ( 25 hepatic and 5 pulmonary) took place during conventional surgical interventions, which occurred between 2004 and 2014. According to WHO-IWGE classification (Pawlowski et al. 2001), hepatic cysts were categorized as follows: 19 cysts were CE1 (76\%), 2 cysts as CE2 (8\%), and 4 cysts as CE3 (16\%). The median age of the patients was $43 \pm 24$ years (min. 10 years, max. 79 years). 


\section{Animal hydatid cysts}

Ten hydatid cysts isolated from Greek animals (3 sheep, 3 buffaloes, 2 goats, and 2 wild boars) were additionally included with the aim to briefly search for common haplotypes circulating in this neighboring countries.

\section{Molecular analyses}

\section{DNA extraction}

Hydatid cysts from Bulgarian patients were stored in $96 \%$ ethanol prior to DNA extraction. Depending on the fertility or infertility of the cysts, genomic DNA (gDNA) was extracted either from protoscoleces or from cyst walls (germinative layers), respectively. The gDNA extraction was carried out using a commercial DNAeasy tissue kit (QIAGEN, Germany). Concerning animal samples, gDNAs were extracted from protoscoleces and/or germinal layers using the DNeasy Blood \& Tissue Kit (QIAGEN, Germany) (Chaligiannis et al. 2015). Subsequently, all isolated gDNAs were checked with NanoDrop 1000 (Thermo scientific) for qualitative and quantitative appropriateness. The gDNA samples were stored at $-20^{\circ} \mathrm{C}$ until use.

\section{Mitochondrial and nuclear gene targets}

In total, eight DNA targets in the $\mathrm{nc}$ and $\mathrm{mt}$ genomes were separately amplified by polymerase chain reaction (PCR). Mitochondrial targets were partial gene sequences coding for cytochrome c oxidase I (cox I) (Bart et al. 2006), NADH dehydrogenase I (nad I) (Bart et al. 2006), the small ribosomal RNA $(r r n \mathrm{~S})$, the large ribosomal RNA ( $r r n \mathrm{~L})$ (Boubaker et al. 2016), and ATP synthase subunit 6 (atp 6). The two primer pairs $r r n S-$ $\mathrm{F} / r r n \mathrm{~S}-\mathrm{R}$ and atp 6-F/atp 6-R were developed in this study.

Nuclear gene markers were covering both coding and/or non-coding sequences, including actin II (actII) (da Silva et al. 1993), homeodomain protein ( $h b \times 2)$ (Haag et al. 1997), and elongation factor $1 \alpha$ (ef-1 $\alpha)$ (Saarma et al. 2009).

The sequences of the primer pairs used are shown in Table 1.

\section{PCR conditions}

PCRs were performed in a $40 \mu \mathrm{l}$ volume containing $4 \mu \mathrm{l}$ DNA (80-200 ng DNA), $100 \mu \mathrm{M}$ dNTPs, $0.5 \mu \mathrm{M}$ of each primer, and $0.4 \mathrm{U}$ Taq polymerasein $1 \times$ PCR Buffer (all Promega, Switzerland). The amplification was carried out in a thermocycler (Biometra T3000 Thermocycler, Labrepco) under the following conditions: an initial start at $94{ }^{\circ} \mathrm{C}$ for $3 \mathrm{~min}$ followed by 35 cycles of $30 \mathrm{~s}$ denaturation at $94{ }^{\circ} \mathrm{C}, 30 \mathrm{~s}$ annealing at optimal temperature for each primer pair as listed in Table 1 , extention at $72{ }^{\circ} \mathrm{C}$ for $90 \mathrm{~s}$ for $e f-1 \alpha$ and $30 \mathrm{~s}$ for the other primers, and a final extention for $5 \mathrm{~min}$ at $72{ }^{\circ} \mathrm{C}$. The electrophoretic resolution of amplificates was performed on $2 \%$ agarose gel stained with ethidium bromide, and the result was visualized under UV light (Syngen, Synoptic group). Sequences with single-point mutations were additionally amplified with High Fidelity Phusion polymerase (Promega, USA) and sequenced as described below for further confirmation of the results.

\section{Sequencing and phylogenetic analyses}

PCR products were purified using High Pure PCR Product Purification Kit (Roche, Switzerland). The automated sequencing was performed with Big Dye kit (Invitrogen) and the Applied Biosystems/Hitachi 3730 DNA analyzer. All amplicons were sequenced in both directions with the corresponding forward and reverse primer (Table 1). The obtained sequences were analyzed using Bioedit version 7.1 software (Hall 1999). The alignments were performed using CrustalW program and sequences were checked manually. The sequences were blasted against available sequences from GenBank database for identification [http://www.ncbi.nlm.nih.gov/]. Phylogenetic analyses were performed with the MEGA 6 software (http: www.megasoftware.net) (Tamura et al. 2013). For the reconstruction of the two phylogenetic trees from the concatenated nc and $\mathrm{mt}$ genes, neighbor-joining (NJ) method was applied (Saitou and Nei 1987) with bootstrap test of 1000 replications (Felsenstein 1985) and Kimura 2-parameter model for the estimation of transitions and transversions (Kimura 1980 ). Taenia solium was used as an outgroup control sequence. Haplotype network was constructed using TCS 1.21 (Clement et al. 2000). Diversity and neutrality indices and divergence (Da) were calculated with the DNASP software (Rozas and Rozas 1995) and MEGA 6. The divergence time (T) between haplotypes was calculated as $\mathrm{T}=\mathrm{Da} / 2 \mu$, where $\mathrm{Da}$ is the divergence between haplotypes and $2 \mu$ is the divergence rate of mtDNA. The divergence rate of mtDNA was accepted to be 2-4\% per 1 million years (Cann et al. 1987).

\section{Statistical methods}

Statistical analyses were performed using SPSS16.0 for Windows. In the study, the following tests were applied: Fisher exact test, Shapiro-Wilks test for normality, KruskalWallis test, and Chi-square test for goodness and fit. Values of $P<0.05$ were considered significant.

\section{Accession numbers}

The accession numbers for the known complete mt genome sequences of E. granulosus s.l. used in this study were as follows: references: G1 (AF297617.1), G3 (KJ559023.1), G4 (AF346403.1), G5 (AB235846.1), G6 (AB208063.1), G7 (AB235847.1), G8 (AB235848.1), G10 (AB745463.1). 
Table 1 List and characteristics of primers used in the study

\begin{tabular}{|c|c|c|c|c|}
\hline Gene & Primer name & Sequence $\left(5^{\prime \prime}-3^{\prime \prime}\right)$. & $\operatorname{Tm}\left({ }^{\circ} \mathrm{C}\right)$ & Ref \\
\hline \multicolumn{5}{|c|}{ mt targets } \\
\hline \multirow[t]{2}{*}{$\operatorname{cox} 1$} & EgCOI1 & TTTTTTGGCCATCCTGAGGTTTAT & 56 & (Bart et al. 2006) \\
\hline & EgCOI2 & TAACGACATAACATAATGAAAATG & & \\
\hline \multirow[t]{2}{*}{ nad 1} & EgNDI1 & AGTCTCGTAAGGGCCCTAACA & 56 & (Bart et al. 2006) \\
\hline & EgNDI2 & CCCGCTGACCAACTCTCTTTC & & \\
\hline \multirow[t]{2}{*}{$r r n S$} & $\operatorname{rrnS}-\mathrm{F}$ & GTTTATCAGTACGAAAGGACAG & 56 & This study \\
\hline & $\operatorname{rrnS}-\mathrm{R}$ & ACACCCTTATTAATGTAACACA & & \\
\hline \multirow[t]{2}{*}{$r r n L$} & $\operatorname{rrnL}-\mathrm{F}$ & TTATTTGCCTTTTGCATCA & 58 & (Boubaker et al. 2016) \\
\hline & $\operatorname{rrnL}-\mathrm{R}$ & AAAAGATCCTAGGGTCTTTCCGT & & \\
\hline \multirow[t]{2}{*}{ atp6 } & atp6-F & TTTGGTCGTGTGTCATATTAC & 56 & This study \\
\hline & atp6-R & CTAATGATCGACTGAAAAATC & & \\
\hline \multicolumn{5}{|c|}{ nc targets } \\
\hline \multirow[t]{2}{*}{ actII } & actII-F & GTCTTCCСCTCTATCGTGGG & 63 & (da Silva et al. 1993) \\
\hline & actII-R & CTAATGAAATTAGTGCTTTGTGCGC & & \\
\hline \multirow[t]{2}{*}{$h b x 2$} & hbx2-F & TTCTCCTCTAGCCAGGTCCA & 63 & (Haag et al. 1997) \\
\hline & hbx2-R & TATAGCGCCGATTCTGGAAC & & \\
\hline \multirow[t]{2}{*}{$e f-1 \alpha$} & ef $-1 \alpha-F$ & TCATTGTTATCGGTCACGTC & 63 & (Saarma et al. 2009) \\
\hline & ef $-1 \alpha-\mathrm{R}$ & CTTCTGGGCAGATTTTGTG & & \\
\hline
\end{tabular}

$\mathrm{Tm}$ annealing temperature
The complete mt genome of $T$. solium was retrieved under this number: NC_004022.1. Accession numbers of references nc targets were as follows: act II (AF528500.1 and AF003749.1), $h b x 2$ (FJ997243.1 and AY129568.1), and ef-1 $\alpha$ (FN568380.1 and FN568384.1). The nucleotide sequences of the E. granulosus s.l. $\mathrm{mt}$ and $\mathrm{n}$ genes identified in this study have been deposited in GenBank under the following accession numbers: with accession numbers KR070964KR070992 (mt-DNA) and KR070993-KR070994 and KR138703-KR138706 (n-DNA).

\section{Results}

Amplification and sequencing were successful for all studied samples and targets, resulting thus in 320 readable sequences, consisting of the following: 334 nucleotides for cox I, 475 for nad I, 406 for $r r n \mathrm{~S}, 605$ for $r r n \mathrm{~L}, 390$ for atp 6, 201 for $h b x 2$, 280 for act II, and 1200 for $e f-1 \alpha$.

\section{Genetic polymorphism among Bulgarian E. granulosus complex human isolates based on mitochondrial markers}

All Bulgarian human cysts were identified as E. granulosus s.s. with a total of 21 identified haplotypes among our datasets including five $\mathrm{mt}$ gene markers: cox I (2 haplotypes; $\mathrm{C} 1$ and C3), nad I (7 haplotypes; N1-N7), rrnS (3 haplotypes; S1-S3), rrnL (4 haplotypes; L1-L4), and atp 6 (5 haplotypes; ATP1ATP5) (Table 2). We found six novel sequences which did not match any sequence in the GenBank database, and they were derived from the following: nad I (2 haplotypes; KR070986 and KR070988), rrnS (1 haplotype KR070971), rrnL (1 haplotype KR070974), and atp6 (2 haplotypes KR070979 and KR070982).

Eleven out of the 21 haplotypes were also detected in the Greek samples (Table 2).

The alignments from the five partial $\mathrm{mt}$ gene sequences were then concatenated to give a single multiple sequence alignment covering $2210 \mathrm{bp}$ and resulting in 10 haplotypes (H1-H6; H9-H12) among Bulgarian E. granulosus s.s. population. Six haplotypes (H1-H6) were identified in 16 human isolates and clustered with E. granulosus s.s. (G1). Four haplotypes (H9-H12), found in 14 isolates, grouped with E. granulosus s.s. (G3) (Table 2 and Fig. 1).

Three haplotypes (H1 (G1), H4 (G1), and H11 (G3)) were shared by samples from Bulgaria and Greece.

One haplotype (H14) was strictly identified in 3 Greek cysts ( 2 goats and 1 wild boar) and was categorized as E. canadensis (G7) (Table 2 and Fig. 1).

In the concatenated sequences, a set of 9 single nucleotide polymorphisms (SNPs) differentiated all E. granulosus s.s. (G1) isolates from E. granulosus s.s. (G3). Two additional SNPs were detected in 12 samples belonging to haplotypes H10-H13 (also in the reference for G3) and differentiate G1 and G3 genotypes of the E. granulosus s.s. (Table 3).

A subset of 286 and 283 SNPs differentiate $E$. canadensis (G7) (H14) from E. granulosus s.s. genotypes G1 (H1) and G3 (H3), respectively. 
Table 2 Concatenated mitochondrial haplotypes detected in this study

\begin{tabular}{|c|c|c|c|c|c|c|c|}
\hline $\begin{array}{l}\text { Haplotype } \\
\text { No. }\end{array}$ & $\operatorname{cox} I^{\mathrm{a}, \mathrm{b}}$ & $\operatorname{nad} I$ & $r r n S$ & $r r n L$ & atp 6 & $\begin{array}{l}\text { No. }{ }^{c} \text { of } \\
\text { BS }\end{array}$ & $\begin{array}{l}\text { No. of } \\
\text { GS }\end{array}$ \\
\hline H1 & $\begin{array}{l}\text { KR070964 } \\
\text { (C1) }\end{array}$ & $\begin{array}{l}\text { KR070984 } \\
\text { (N1) }\end{array}$ & $\begin{array}{l}\text { KR070969 } \\
\text { (S1) }\end{array}$ & $\begin{array}{l}\text { KR070973 } \\
\text { (L1) }\end{array}$ & $\begin{array}{l}\text { KR070978 } \\
\text { (ATP1) }\end{array}$ & 11 & 2 \\
\hline $\mathrm{H} 2$ & $\begin{array}{l}\text { KR070964 } \\
\text { (C1) }\end{array}$ & $\begin{array}{l}\text { KR070986 } \\
\text { (N3) }\end{array}$ & $\begin{array}{l}\text { KR070969 } \\
\quad(\mathrm{S} 1)\end{array}$ & $\begin{array}{l}\text { KR070973 } \\
\text { (L1) }\end{array}$ & $\begin{array}{l}\text { KR070978 } \\
\text { (ATP1) }\end{array}$ & 1 & - \\
\hline $\mathrm{H} 3$ & $\begin{array}{l}\text { KR070964 } \\
\text { (C1) }\end{array}$ & $\begin{array}{l}\text { KR070988 } \\
\text { (N5) }\end{array}$ & $\begin{array}{l}\text { KR070969 } \\
\quad(\mathrm{S} 1)\end{array}$ & $\begin{array}{l}\text { KR070974 } \\
\text { (L2) }\end{array}$ & $\begin{array}{l}\text { KR070978 } \\
\text { (ATP1) }\end{array}$ & 1 & - \\
\hline $\mathrm{H} 4$ & $\begin{array}{l}\text { KR070964 } \\
\text { (C1) }\end{array}$ & $\begin{array}{l}\text { KR070985 } \\
\text { (N2) }\end{array}$ & $\begin{array}{l}\text { KR070969 } \\
\quad(\mathrm{S} 1)\end{array}$ & $\begin{array}{l}\text { KR070973 } \\
\text { (L1) }\end{array}$ & $\begin{array}{l}\text { KR070978 } \\
\text { (ATP1) }\end{array}$ & 1 & 1 \\
\hline H5 & $\begin{array}{l}\text { KR070964 } \\
\text { (C1) }\end{array}$ & $\begin{array}{l}\text { KR070989 } \\
\text { (N6) }\end{array}$ & $\begin{array}{l}\text { KR070969 } \\
\quad(\mathrm{S} 1)\end{array}$ & $\begin{array}{l}\text { KR070973 } \\
\text { (L1) }\end{array}$ & $\begin{array}{l}\text { KR070978 } \\
\text { (ATP1) }\end{array}$ & 1 & - \\
\hline H6 & $\begin{array}{l}\text { KR070964 } \\
\text { (C1) }\end{array}$ & $\begin{array}{l}\text { KR070987 } \\
\text { (N4) }\end{array}$ & $\begin{array}{l}\text { KR070969 } \\
\quad(\mathrm{S} 1)\end{array}$ & $\begin{array}{l}\text { KR070973 } \\
\text { (L1) }\end{array}$ & $\begin{array}{l}\text { KR070979 } \\
\text { (ATP2) }\end{array}$ & 1 & - \\
\hline H7 & $\begin{array}{l}\text { KR070965 } \\
(\mathrm{C} 2)\end{array}$ & $\begin{array}{l}\text { KR070984 } \\
\text { (N1) }\end{array}$ & $\begin{array}{l}\text { KR070969 } \\
\quad(\mathrm{S} 1)\end{array}$ & $\begin{array}{l}\text { KR070973 } \\
\text { (L1) }\end{array}$ & $\begin{array}{l}\text { KR070978 } \\
\text { (ATP1) }\end{array}$ & - & 1 \\
\hline H8 & $\begin{array}{l}\text { KR070964 } \\
\text { (C1) }\end{array}$ & $\begin{array}{l}\text { KR070991 } \\
\text { (N8) }\end{array}$ & $\begin{array}{l}\text { KR070969 } \\
\quad(\mathrm{S} 1)\end{array}$ & $\begin{array}{l}\text { KR070973 } \\
\text { (L1) }\end{array}$ & $\begin{array}{l}\text { KR070978 } \\
\text { (ATP1) }\end{array}$ & - & 1 \\
\hline H9 & $\begin{array}{l}\text { KR070966 } \\
\text { (C3) }\end{array}$ & $\begin{array}{l}\text { KR070990 } \\
\text { (N7) }\end{array}$ & $\begin{array}{l}\text { KR070970 } \\
\text { (S2) }\end{array}$ & $\begin{array}{l}\text { KR070976 } \\
\text { (L4) }\end{array}$ & $\begin{array}{l}\text { KR070981 } \\
\text { (ATP4) }\end{array}$ & 4 & - \\
\hline H10 & $\begin{array}{l}\text { KR070966 } \\
\text { (C3) }\end{array}$ & $\begin{array}{l}\text { KR070990 } \\
\text { (N7) }\end{array}$ & $\begin{array}{l}\text { KR070970 } \\
\text { (S2) }\end{array}$ & $\begin{array}{l}\text { KR070975 } \\
\text { (L3) }\end{array}$ & $\begin{array}{l}\text { KR070980 } \\
\text { (ATP3) }\end{array}$ & 8 & - \\
\hline H11 & $\begin{array}{l}\text { KR070966 } \\
\text { (C3) }\end{array}$ & $\begin{array}{l}\text { KR070990 } \\
\text { (N7) }\end{array}$ & $\begin{array}{l}\text { KR070971 } \\
\text { (S3) }\end{array}$ & $\begin{array}{l}\text { KR070975 } \\
\quad \text { (L3) }\end{array}$ & $\begin{array}{l}\text { KR070980 } \\
\text { (ATP3) }\end{array}$ & 1 & 1 \\
\hline H12 & $\begin{array}{l}\text { KR070966 } \\
\text { (C3) }\end{array}$ & $\begin{array}{l}\text { KR070990 } \\
\text { (N7) }\end{array}$ & $\begin{array}{l}\text { KR070970 } \\
\text { (S2) }\end{array}$ & $\begin{array}{l}\text { KR070975 } \\
\quad \text { (L3) }\end{array}$ & $\begin{array}{l}\text { KR070982 } \\
\text { (ATP5) }\end{array}$ & 1 & - \\
\hline H13 & $\begin{array}{l}\text { KR070967 } \\
\text { (C4) }\end{array}$ & $\begin{array}{l}\text { KR070990 } \\
\text { (N7) }\end{array}$ & $\begin{array}{l}\text { KR070970 } \\
\text { (S2) }\end{array}$ & $\begin{array}{l}\text { KR070975 } \\
\quad \text { (L3) }\end{array}$ & $\begin{array}{l}\text { KR070980 } \\
\text { (ATP3) }\end{array}$ & - & 1 \\
\hline H14 & $\begin{array}{l}\text { KR070968 } \\
\text { (C5) }\end{array}$ & $\begin{array}{l}\text { KR070992 } \\
\text { (N9) }\end{array}$ & $\begin{array}{l}\text { KR070972 } \\
\text { (S4) }\end{array}$ & $\begin{array}{l}\text { KR070977 } \\
\text { (L5) }\end{array}$ & $\begin{array}{l}\text { KR070983 } \\
\text { (ATP6) }\end{array}$ & - & 3 \\
\hline
\end{tabular}

${ }^{a}$ Accession number in GenBank of each individual gene markers

${ }^{\mathrm{b}}$ Designation of the haplotype in the individual genes is given in parenthesis

${ }^{\mathrm{c}}$ Number of Bulgarian (BS) and Greek samples (GS) with each haplotype
The network of mt haplotypes based on the concatenated sequences was drawn to evaluate relationships among the different E. granulosus s.s. haplotypes (Fig. 2). Thus, haplotype H1 was inferred as the hypothetical ancestral haplotype. H2H8 differed from $\mathrm{H} 1$ in 1 to 2 mutational steps. H8 presented as an intermediate ancestral haplotype to H2. H9-H13 differed from $\mathrm{H} 1$ by 9 to 12 mutational steps. H9 appeared as an intermediate ancestral haplotype to H10, and H10 appeared as an ancestral haplotype to $\mathrm{H} 11-\mathrm{H} 13$, which differed from each other by single-point mutations (Fig. 2).

The divergence between haplotypes $\mathrm{H} 1$ and $\mathrm{H} 9$ was $\mathrm{Da}=0.00407(0.41 \%)$, between $\mathrm{H} 1$ and $\mathrm{H} 10$ was $\mathrm{Da}=0.0054(0.54 \%)$, and between $\mathrm{H} 9$ and $\mathrm{H} 10$ was $\mathrm{Da}=0.0009(0.09 \%)$. The divergence time between $\mathrm{H} 1$ and H9 was estimated at 100,000-200,000 years of evolution, between $\mathrm{H} 1$ and $\mathrm{H} 10$ at 135,000-270,000 years of evolution, and between $\mathrm{H} 9$ and $\mathrm{H} 10$ at 35,000-70,000 years of evolution. Data for the diversity and neutrality indices of
E. granulosus s.s.in the Bulgarian and Greek samples from the $5 \mathrm{mt}$ targets are shown in Table 4.

\section{Genetic polymorphism among Bulgarian E. granulosus Complex human isolates based on nuclear markers}

For each of the three investigated nc markers (act II, hbx, and ef-1 $\alpha$ ), all Bulgarian human isolates were showing identical sequences and formed one cluster with E. granulosus s.s. (G1/ G2/G3) (Table 5 and Fig. 3).

The concatenated sequences of the partial nc genes consisted of 1521 readable nucleotides and they formed one single E. granulosus s.s. (G1/G2/G3) haplotype (N1) for all Bulgarian human cysts. This later haplotype (N1) was also present in Greek samples, where additionally one more haplotype (N2) was detected, referring to E. canadensis (G6-G8, G10) (Table 5). Within the present study sample collection, 
Fig. 1 Dendrogram of concatenated sequences (haplotypes H1-H14) of Bulgarian and Greek samples and references for genotypes G1-G8 and G10. The neighbor-joining method with Kimura 2-parameter method and bootstrap test (1000 replicates) was applied. Taenia solium (T. $s$ ) was used as outgroup. The numbers next to the branches represent the percentage of replicate trees, in which the associated taxa cluster together in the bootstrap test

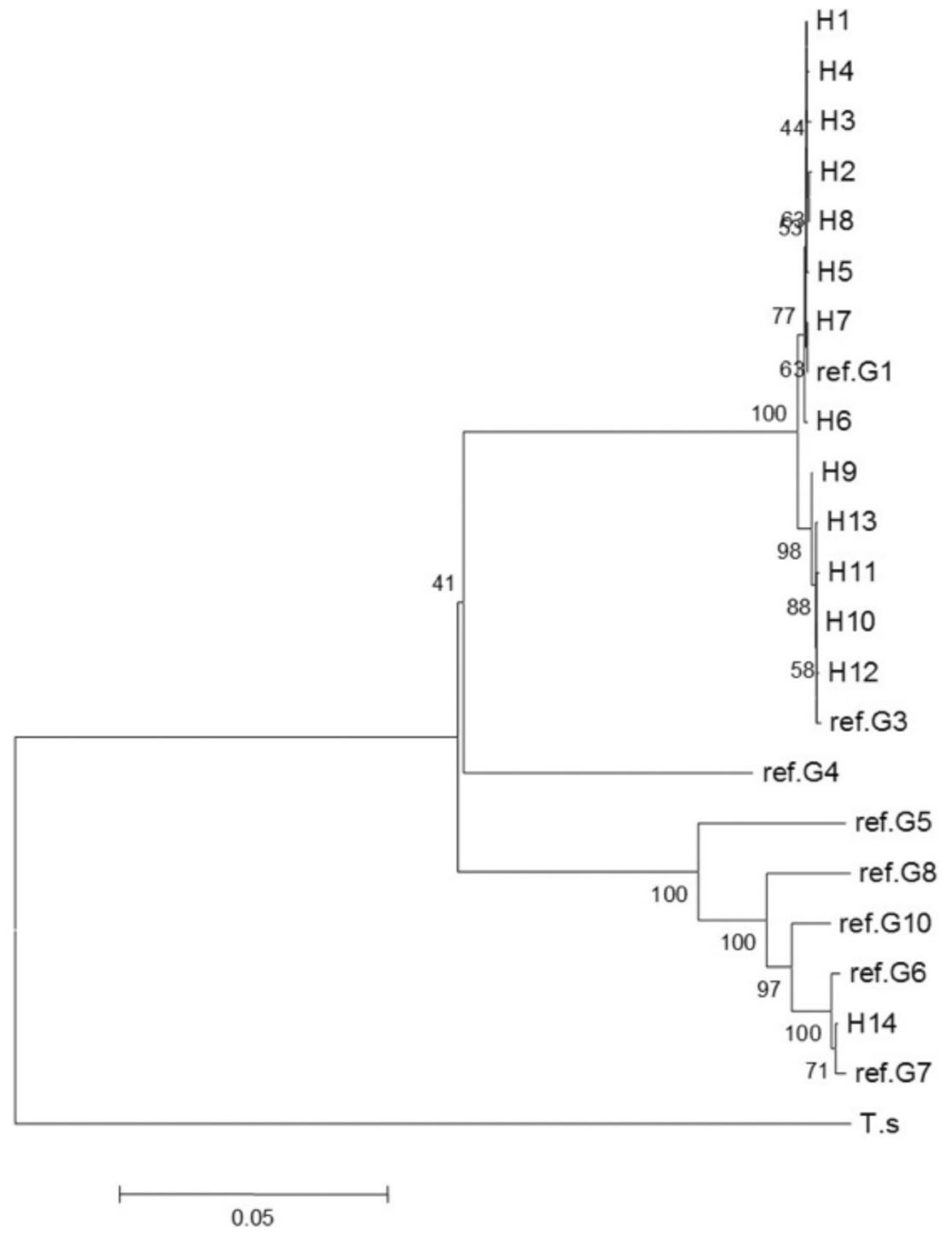

we report a total of 32 SNPs distinguishing between N1 (E. granulosus s.s.) and N2 (E. canadensis).

The sequences in the present study are deposited in GenBank under following accession numbers KR070993KR070994 (ef-1 $\alpha$ ), KR138703-KR138704 (act II), and KR138705-KR138706 (hbx).

\section{Geographical distribution and correlation of $E$. granulosus s.s. haplotypes with human CE in Bulgaria}

The analysis of $\mathrm{mt}$ and nc genome sequences revealed that the Bulgarian samples belonged to E. granulosus s.s. Based on $\mathrm{mt}$ genomes, 16 isolates clustered with the reference for genotype G1 and 14 with genotype G3. In order to compare the samples, we divided them into these two clusters E. granulosus s.s. (G1) and E. granulosus s.s. (G3). The geographical distribution revealed that they were evenly spread across the territory of Bulgaria, and in some regions, where more samples were collected, they occurred sympatrically, although in different patients. Comparison according to the gender of the patients, age, and location of the cyst did not show statistically significant difference between the two groups (Fisher exact test, $P>0.05$ ). The median values of the cyst size of G1 $(6.6 \mathrm{~cm} \pm 3.5 \mathrm{SD})$ and $\mathrm{G} 3(5.5 \mathrm{~cm} \pm 3.8 \mathrm{SD})$ showed again a lack of statistically significant difference (Shapiro-Wilks test for normality $P<0.01$; Kruskal-Wallis test $1.906, P>0.05$ ). According to the ultrasound classification of the liver cysts, the predominant form in both groups was CE1 (84\% in G1 and $75 \%$ in G3), the results being statistically significant (Chi-square test14.965 and 9.5 for G1 and G3, respectively, $P<0.05$ ).

\section{Discussion}

All 30 Bulgarian CE patients included in this study, who underwent surgery for removal of hepatic or pulmonary $\mathrm{CE}$ 


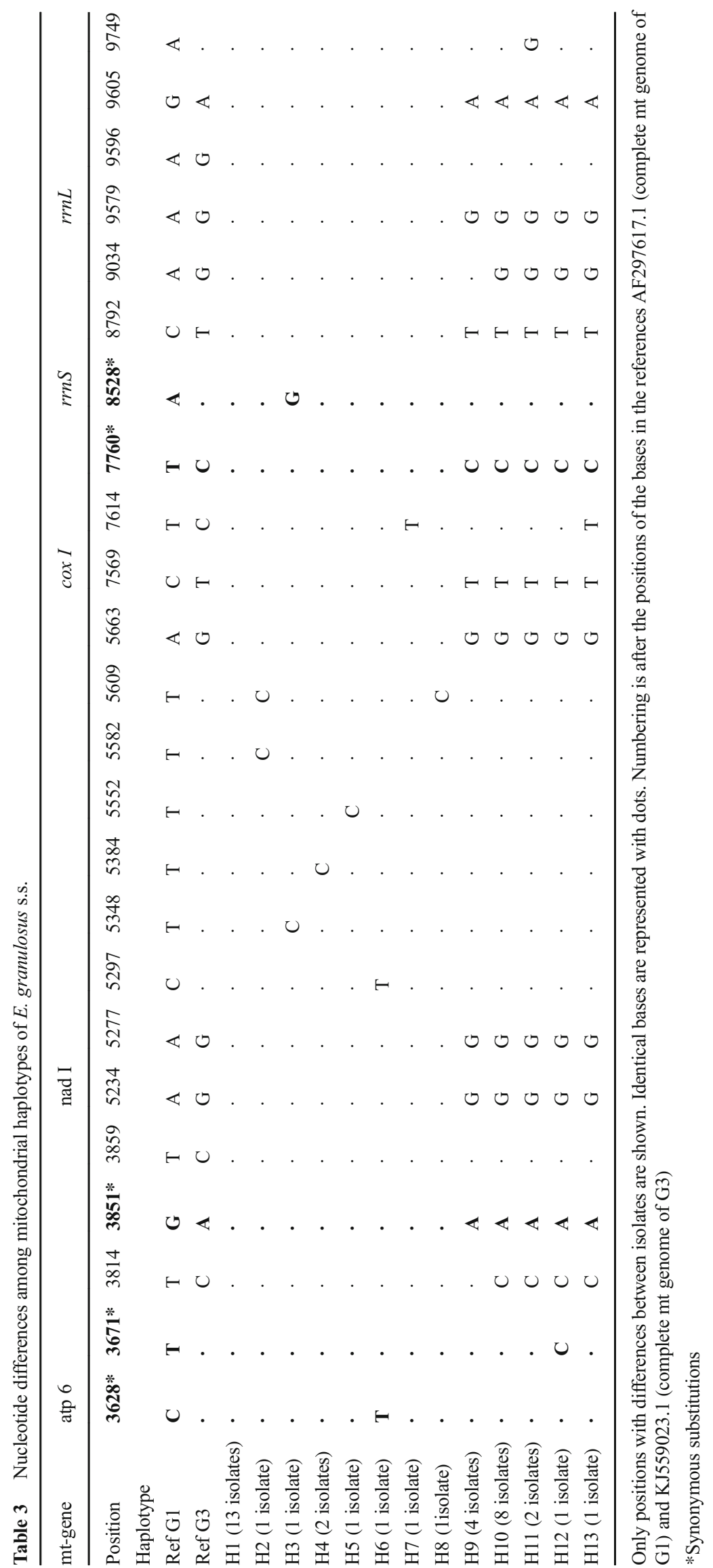


Fig. 2 Haplotype network of concatenated sequences (H1H13) of Bulgarian and Greek E. granulosus s.s. samples, composed from the mitochondrial genes. The rectangle represents the hypothetical ancestral haplotype (the outgroup) and the ovals are haplotypes arising from it. Their size is equivalent to the number of haplotypes. Branches represent point mutations and the dots on them are hypothetical missing haplotypes

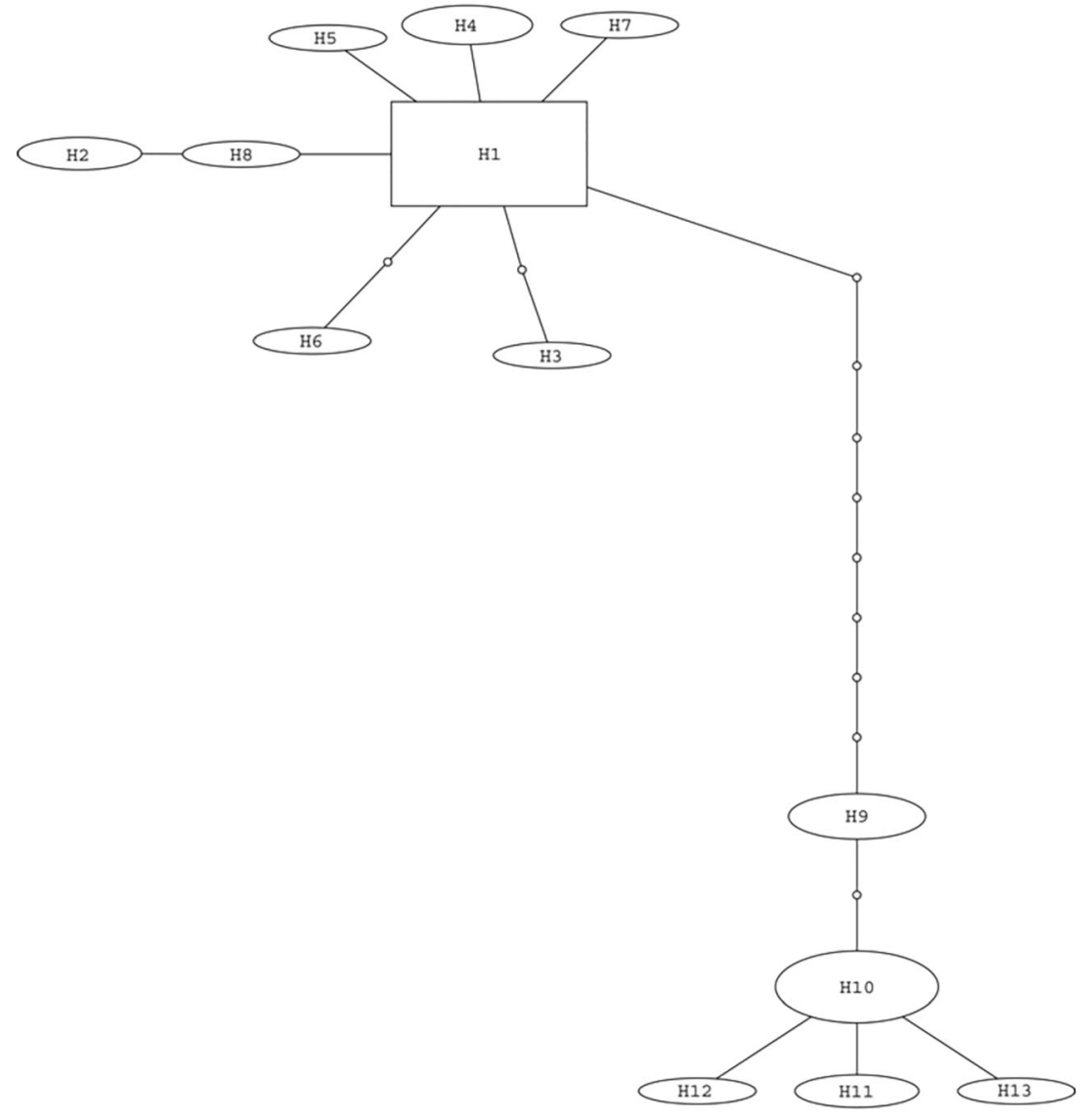

between 2004 and 2014, were found to be infected with either the E. granulosus s.s. G1 or G3 genotype. These findings were in agreement with previous reports that had already documented the presence of G1 and G3 in humans (Casulli et al. 2012) and livestock (Breyer et al. 2004; Boubaker et al. 2013) in Bulgaria. Although CE with G2 had also been previously recorded in Bulgaria (Casulli et al. 2012), G2 was not found in our study. Overall, G2 is principally not well characterized yet, and especially, its complete mt genome is still missing.
Genotype G2 is often described as a micro-variant of G1 or of G3 (Snabel et al. 2009; Alvarez et al. 2014).

In our study, we found an amazingly high rate (47\%) of human $\mathrm{CE}$ cases to be associated with E. granulosus s.s. (G3); high rates of human infection with $\mathrm{G} 3$ were previously reported from Italy (Latium: 87\%) (Busi et al. 2007), India (North India: 53.1\%) (Sharma etal. 2013a), and Iran (Ardabil Province: 22\%) (Pezeshki et al. 2013); additionally, G3 is infecting humans in
Table 4 Diversity and neutrality indexes of $E$. granulosus s.s. in Bulgarian $(n=30)$ and Greek $(n=7)$ samples in the studied genetic markers

\begin{tabular}{rlllllrr}
\hline Gene & Country & Haplotypes & S & Haplotype diversity & $\begin{array}{l}\text { Nucleotide } \\
\text { diversity }\end{array}$ & D & Fs \\
& & & & & & \\
\hline cox I & BG & 2 & 2 & $0.515 \pm 0.027$ & $0.003 \pm 0.001$ & 2.130 & 3.459 \\
& Gr & 4 & 3 & $0.714 \pm 0.181$ & $0.004 \pm 0.003$ & 1.220 & -0.780 \\
nad I & BG & 7 & 9 & $0.664 \pm 0.059$ & $0.004 \pm 0.002$ & -0.447 & -0.537 \\
& Gr & 4 & 5 & $0.810 \pm 0.130$ & $0.004 \pm 0.003$ & -0.099 & -0.132 \\
$r r n S$ & BG & 3 & 3 & $0.545 \pm 0.042$ & $0.003 \pm 0.001$ & 1.054 & 1.868 \\
& Gr & 3 & 3 & $0.524 \pm 0.209$ & $0.003 \pm 0.002$ & 0.050 & 0.406 \\
$r r n L$ & BG & 4 & 3 & $0.664 \pm 0.050$ & $0.002 \pm 0.001$ & 0.890 & 0.512 \\
& Gr & 2 & 2 & $0.476 \pm 0.171$ & $0.002 \pm 0.001$ & 0.687 & 1.702 \\
$\operatorname{atp} 6$ & BG & 5 & 4 & $0.662 \pm 0.061$ & $0.003 \pm 0.001$ & 0.250 & -0.360 \\
& Gr & 2 & 2 & $0.476 \pm 0.171$ & $0.002 \pm 0.002$ & 0.687 & 1.702 \\
\hline
\end{tabular}

$B G$ Bulgaria $G r$ Greece $S$ number of segregating sites $D$ Tajima's statistics $F s$ Fu's statistics 
Table 5 Nuclear haplotypes resulted from concatenated sequences

\begin{tabular}{|c|c|c|c|c|c|c|}
\hline Haplotype & $\begin{array}{l}\text { Accession number and } \\
\text { (haplotype name) }\end{array}$ & & & Genetic identidy & No. & \\
\hline & Act II & $\mathrm{Hbx} 2$ & Ef- $1 \alpha$ & & $\mathrm{BS}$ & GS \\
\hline N1 & $\begin{array}{l}\text { KR138703 } \\
(\mathrm{AC} 1)\end{array}$ & $\begin{array}{l}\text { KR138705 } \\
\text { (HB1) }\end{array}$ & $\begin{array}{l}\text { KR070993 } \\
(\mathrm{EF} 1)\end{array}$ & $\begin{array}{l}\text { E. granulosus s.s. } \\
\text { (G1/G2/G3) }\end{array}$ & 30 & 7 \\
\hline N2 & $\begin{array}{l}\text { KR138704 } \\
(\mathrm{AC} 2)\end{array}$ & $\begin{array}{l}\text { KR138706 } \\
\text { (HB2) }\end{array}$ & $\begin{array}{l}\text { KR070994 } \\
\text { (EF2) }\end{array}$ & $\begin{array}{l}\text { E. canadensis } \\
\text { (G6-G8, G10) }\end{array}$ & - & 3 \\
\hline
\end{tabular}

No. number of samples $B S$ Bulgarian samples GS Greek samples
Turkey (Simsek et al. 2011), Tunisia (M'rad et al. 2010), Algeria (Zait et al. 2016), and China (Yan et al. 2016).

Molecular data on animal and human cysts showed that, over the world, the G3 genotype, known as "buffalo strain," is expanding in geographic extent as well as in IH range's diversity; larval stage of G3 can be hosted by sheep (Busi et al. 2007), cattle (Busi et al. 2007), camels (Sharbatkhori et al. 2011), Nilelechwe (Busi et al. 2007), goats (Calderini et al. 2012), and pigs (Pednekar et al. 2009). The E. granulosus s.s. (G3) is now circulating in almost all continents: Asia (Sharma et al. 2013a, b; Wang et al. 2015), Africa (M'rad et al. 2010; Zait et al. 2016), South America (Cucher et al. 2016), Europe (Busi et al. 2007; Casuli et al. 2012), and Australia (Guo et al. 2011). Thus, even though that CE infection in humans and animals is more associated with E. granulosus s.s. (G1), the real contribution of $\mathrm{G} 3$ to the global burden of $\mathrm{CE}$ could have been underestimated. In fact, the genetic differentiation potential between G1 and G3 is low and can only be reliably tracked upon mtDNA analyses. Genotypic characterization of E. granulosus s.s. specimens widely depends upon the resolving power of the genetic markers used; indeed, in many reports, human cysts were characterized referring to the species name $E$. granulosus s.s., without determining the corresponding genotype (Piccoli et al. 2013; Mutwiri et al. 2013; Bakal et al. 2015; Boufana et al. 2015; Wang et al. 2015).

Besides the identification of the E. granulosus s.s. G1 (50\%) and G3 (20\%) genotypes in the Greek samples, E. canadensis (G7) isolates were revealed in two goats and in a wild boar.
As in the five countries bordering Bulgaria, namely Greece, Romania, Turkey, Serbia, and Republic of Macedonia, both E. granulosus s.s. (G1/G2/G3) and E. canadensis $(\mathrm{G} 7)$ were found in both humans and livestock, our findings were expected (Bart et al. 2006; Varcasia et al. 2007; Maillard et al. 2009; Snabel et al. 2009; Schneider et al. 2010; Casulli et al. 2012; Bobic et al. 2012; Piccoli et al. 2013). However, the lack of E. canadensis (G7) detectability in our Bulgarian study group has to be interpreted with caution, since the number of respective samples examined (cysts from 25 livers and 5 lungs) is a limiting factor for excluding the occurrence of E. canadensis (G7), and we may need a much larger study group to allow a statistically significant exclusion of G7 as an infection organism in the Bulgarian human population (Breyer et al. 2004; Casulli et al. 2012). This relativation of our interpretation is underlined by other similar studies, where human CE cases with hepatic and pulmonary infections due to the E. canadensis $\mathrm{G} 7$ were recorded (Schneider et al. 2010; Zhang et al. 2014; Dybicz et al. 2015). In some other areas, E. canadensis (G7) appeared even as the predominant cause of human $\mathrm{CE}$, such as in Poland and Austria (Romig et al. 2015).

In contrast to Echinococcus nuclear genes where only interspecies differentiation occurs, three levels of discrimination became possible when using partial mt DNA sequences, including species, genotypes, and haplotypes. A significant discrepancy between the nuclear and mitochondrial phylogenies of the E. granulosus complex was previously reported by

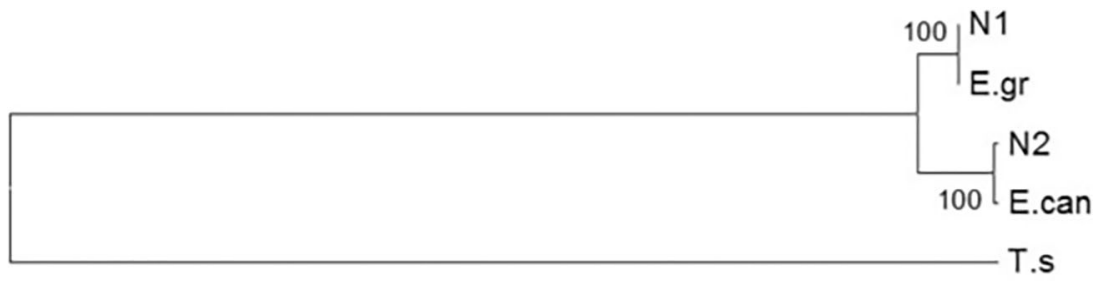

0.02

Fig. 3 Dendrogram of concatenated sequences (haplotypes N1-N2) of Bulgarian and Greek samples with regard to the nuclear genes. The neighbor-joining method with Kimura 2-parameter method and bootstrap test (1000 replicates) was applied. Taenia solium (T.s) was used as an outgroup control. The numbers next to the branches represent the percentage of replicate trees in which the associated taxa cluster together in the bootstrap test. Ts Taenia solium, Egr reference for E. granulosus s.s., Ecan reference for E. canadensis 
others (Bart et al. 2006; Saarma et al. 2009; Knapp et al. 2011; Sharbatkhori et al. 2011).

With regard to haplotype characterization, we detected 21 distinct mt DNA haplotypes in Bulgarian samples based on sequence analyses of cox I (C1_C2), nad I (ND1_ND7), rrnS (S1 S3), rrnL (L1 L4), and atp 6 (ATP1 ATP5), with three haplotypes-ND1 (Breyer et al. 2004), C1 (Casulli et al. 2012), and C2 (Casulli et al. 2012) having already previously been described in Bulgaria.

In our study, nad 1 was the fastest mutating mt gene in both Bulgarian and Greek populations, and this finding is in line with a recent study showing that nad 2 is the fastest evolving $\mathrm{mt}$ gene in Echinococcus (Wang et al. 2014).

In our study, the analysis of the concatenated sequences of the five $\mathrm{mt}$ genes from Bulgarian and Greek isolates resulted in a total of 14 haplotypes. In the haplotype network, H1 appeared as the hypothetical ancestral haplotype of all other haplotypes reported herein. The highest divergence time in the Bulgarian populations (between $\mathrm{H} 1$ and $\mathrm{H} 10$ ) was estimated to be $135,000-270,000$ years of evolution. This finding is actually very similar with the results published for the common ancestor of all surviving mt types in humans, which was estimated at 140,000-290,000 years (Cann et al. 1987).

Overall, although the molecular typing of the E. granulosus complex has begun more than 20 years ago (Bowles et al. 1992a, b), nowadays, we still do not know all details about possible differential clinical patterns of human CE across species and genotypes of this complex. It has been suggested that in humans, the E. canadensis (G6) larvae has higher affinity to brain than other organs (Sadjjadi et al. 2013). Similarly, in another study, patients with hepatic $\mathrm{CE}$ and infected with $\mathrm{G} 7$ appeared to harbor larger cysts than those infected with the G1 genotype (Schneider et al. 2010). In our study, we could not detect any association between distinct $E$. granulosus s.s. genotypes (G1 and G3) and clinical (cyst localization, cyst size) and demographic (age and gender) features of CE patients. Furthermore, liver cysts of both G1 and G3 were predominantly classified as CE-1 ( $84 \%$ G1 and $75 \% \mathrm{G} 3$ ), according to the WHO-IWGE sonographic classification of echinococcal cysts (Pawlowski et al. 2001). In another study from Poland, among seven liver cysts due to the E. canadensis (G7), four were of CE-2 (Dybicz et al. 2015).

In summary, and to the best of our knowledge, we provide the first relatively large report series on molecular epidemiology of human CE in Bulgaria. Our findings highlight roles of E. granulosus s.s. (genotype G1 and G3) as the sole cause of hydatid disease in Bulgaria; nevertheless, the reason for lack of E. canadensis (G7) remains still open and needs further investigations. The results presented here may have implications in planning and implementing of effective strategies and public health policies towards a better control for $\mathrm{CE}$ in Bulgaria.

Acknowledgements This work was funded by Swiss National Science Foundation (grant number 31003A_141039/1).

\section{References}

Alvarez Rojas CA, Romig T, Lightowlers MW (2014) Echinococcus granulosus sensu lato genotypes infecting humans - review of current knowledge. Int J Parasitol 44:9-18. doi:10.1016/j. ijpara.2013.08.008

Bakal U, Simsek S, Kazez A (2015) Surgical and molecular evaluation of pediatric hydatid cyst cases in eastern Turkey. Korean J Parasitol 53: 785-788. doi:10.3347/kjp.2015.53.6.785

Bart JM, Morariu S, Knapp J, Ilie MS, Pitulescu M, Anghel A et al (2006) Genetic typing of Echinococcus granulosus in Romania. Parasitol Res 98:130-137. doi:10.1007/s00436-005-0015-9

Beato S, Parreira R, Calado M, Grácio MAA (2010) Apparent dominance of the G1-G3 genetic cluster of Echinococcus granulosus strains in the central inland region of Portugal. Parasitol Int 59:638-642. doi:10.1016/j.parint.2010.08.004

Bobić B, Nikolić A, Radivojević SK, Klun I, Djurković-Djaković O (2012) Echinococcosis in Serbia: an issue for the twenty-first century? Foodborne Pathog Dis 9:967-973. doi:10.1089/fpd.2012.1227

Boubaker G, Macchiaroli N, Prada L, Cucher MA, Rosenzvit MC, Ziadinov I et al (2013) A multiplex PCR for the simultaneous detection and genotyping of the Echinococcus granulosus complex. PLoS Negl Trop Dis 7:e2017. doi:10.1371/journal.pntd.0002017

Boubaker G, Marinova I, Gori F, Hizem A, Müller N, Casulli A et al (2016) A dual PCR-based sequencing approach for the identification and discrimination of Echinococcus and Taenia taxa. Mol Cell Probes 30:211-217. doi:10.1016/j.mcp.2016.05.004

Boufana B, Lett WS, Lahmar S, Buishi I, Bodell AJ, Varcasia A et al (2015) Echinococcus equinus and Echinococcus granulosus sensu stricto from the United Kingdom: genetic diversity and haplotypic variation. Int J Parasitol 45:161-166. doi:10.1016/j. ijpara.2014.10.005

Bowles J, Blair D, McManus DP (1992a) Genetic variants within the genus Echinococcus identified by mitochondrial DNA sequencing. Mol Biochem Parasitol 54:165-173

Bowles J, van Knapen F, McManus D (1992b) Cattle strain of Echinococcus granulosus and human infection. Lancet 339:1358

Bowles J, McManus DP (1993) NADH dehydrogenase 1 gene sequences compared for species and strains of the genus Echinococcus. Int $\mathrm{J}$ Parasitol 23:969-972

Bowles J, Blair D, McManus DP (1994) Molecular genetic characterization of the cervid strain ('northern form') of Echinococcus granulosus. Parasitology 109:215-221

Breyer I, Georgieva D, Kurdova R, Gottstein B (2004) Echinococcus granulosus strain typing in Bulgaria: the G1 genotype is predominant in intermediate and definitive wild hosts. Parasitol Res 93:127130. doi:10.1007/s00436-004-1116-6

Busi M, Snábel V, Varcasia A, Garippa G, Perrone V, De Liberato C et al (2007) Genetic variation within and between G1 and G3 genotypes of Echinococcus granulosus in Italy revealed by multilocus DNA sequencing. Vet Parasitol 150:75-83. doi:10.1016/j. vetpar.2007.09.003

Calderini P, Gabrielli S, Cancrini G (2012) Is the goat a new host for the G3 Indian buffalo strain of Echinococcus granulosus? ScientificWorldJournal 2012:286357. doi:10.1100/2012/286357

Cann RL, Stoneking M, Wilson AC (1987) Mitochondrial DNA and human evolution. Nature 325:31-36. doi:10.1038/325031a0

Casulli A, Interisano M, Sreter T, Chitimia L, Kirkova Z, La Rosa G et al (2012) Genetic variability of Echinococcus granulosus sensu stricto in Europe inferred by mitochondrial DNA sequences. Infect Genet Evol 12:377-383. doi:10.1016/j.meegid.2011.12.014

Chaligiannis I, Maillard S, Boubaker G, Spiliotis M, Saratsis A, Gottstein $\mathrm{B}$ et al (2015) Echinococcus granulosus infection dynamics in livestock of Greece. Acta Trop 150:64-70. doi:10.1016/j. actatropica.2015.06.021 
Clement M, Posada D, Crandall KA (2000) TCS: a computer program to estimate gene genealogies. Mol Ecol 9:1657-1659

Cucher MA, Macchiaroli N, Baldi G, Camicia F, Prada L, Maldonado L et al (2016) Cystic echinococcosis in South America: systematic review of species and genotypes of Echinococcus granulosus sensu lato in humans and natural domestic hosts. Tropical Med Int Health 21:166-175. doi:10.1111/tmi.12647

da Silva CM, Henrique, Ferreira B, Picón M, Gorfinkiel N, Ehrlich R et al (1993) Molecular cloning and characterization of actin genes from Echinococcus granulosus. Mol Biochem Parasitol 60:209-219

Dybicz M, Borkowski PK, Dąbrowska J, Chomicz L (2015) Cases of Echinococcus gramulosus sensu stricto isolated from polish patients: imported or indigenous? Biomed Res Int 2015:728321. doi:10.1155/2015/728321

Eckert J, Deplazes P (2004) Biological, epidemiological, and clinical aspects of echinococcosis, a zoonosis of increasing concern. Clin Microbiol Rev 17:107-135. doi:10.1128/CMR.17.1.107-135.2004

Eurosurveillance Editorial Team (2013) The European Union summary report on trends and sources of zoonoses, zoonotic agents and foodborne outbreaks in 2011 has been published. Euro Surveill 18: pii $=20449$. http://www.eurosurveillance.org/ViewArticle. aspx?ArticleId $=20449$

Felsenstein J (1985) Confidence limits on phylogenies: an approach using the bootstrap. Evolution 39:783-791. doi:10.2307/2408678

Guo ZH, Kubo M, Kudo M, Nibe K, Horii Y, Nonaka N (2011) Growth and genotypes of Echinococcus granulosus found in cattle imported from Australia and fattened in Japan. Parasitol Int 60:498-502. doi:10.1016/j.parint.2011.09.002

Haag KL, Zaha A, Araújo AM, Gottstein B (1997) Reduced genetic variability within coding and non-coding regions of the Echinococcus multilocularis genome. Parasitology 115:521-529

Hall T (1999) BioEdit: a user-friendly biological sequence alignment editor and analysis program for windows 95/98/NT. Nucleic Acids Symp Ser 41:95-98

Hüttner M, Nakao M, Wassermann T, Siefert L, Boomker JDF, Dinkel A et al (2008) Genetic characterization and phylogenetic position of Echinococcus felidis (Cestoda: Taeniidae) from the African lion. Int J Parasitol 38:861-868. doi:10.1016/j.ijpara.2007.10.013

Jenkins DJ, Romig T, Thompson RCA (2005) Emergence/re-emergence of Echinococcus spp.-a global update. Int J Parasitol 35:1205-1219. doi:10.1016/j.ijpara.2005.07.014

Jordanova DP, Harizanov RN, Kaftandjiev IT, Rainova IG, Kantardjiev TV (2015) Cystic echinococcosis in Bulgaria 1996-2013, with emphasis on childhood infections. Eur J Clin Microbiol Infect Dis 34: 1423-1428. doi:10.1007/s10096-015-2368-Z

Knapp J, Nakao M, Yanagida T, Okamoto M, Saarma U, Lavikainen A et al (2011) Phylogenetic relationships within Echinococcus and Taenia tapeworms (Cestoda: Taeniidae): an inference from nuclear protein-coding genes. Mol Phylogenet Evol 61:628-638. doi:10.1016/j.ympev.2011.07.022

Kimura M (1980) A simple method for estimating evolutionary rates of base substitutions through comparative studies of nucleotide sequences. J Mol Evol 16:111-120

Lavikainen A, Lehtinen MJ, Meri T, Hirvelä-Koski V, Meri S (2003) Molecular genetic characterization of the Fennoscandian cervid strain, a new genotypic group (G10) of Echinococcus granulosus. Parasitology 127:207-215

Lymbery AJ, Jenkins EJ, Schurer JM, Thompson RCA (2015a) Echinococcus canadensis, E. borealis, and E. intermedius. What's in a name? Trends Parasitol 31:23-29. doi:10.1016/j.pt.2014.11.003

Lymbery AJ, Jenkins EJ, Schurer JM, Thompson RCA, Response to Nakao et al (2015b) Is Echinococcus intermedius a valid species? Trends Parasitol 31:343-344. doi:10.1016/j.pt.2015.05.005

Maillard S, Gottstein B, Haag KL, Ma S, Colovic I, Benchikh-Elfegoun MC et al (2009) The EmsB tandemly repeated multilocus microsatellite: a new tool to investigate genetic diversity of Echinococcus granulosus sensu lato. JClin Microbiol 47:3608-3616. doi:10.1128/JCM.00938-09
Moks E, Jõgisalu I, Valdmann H, Saarma U (2008) First report of Echinococcus granulosus G8 in Eurasia and a reappraisal of the phylogenetic relationships of "genotypes" G5-G10. Parasitology 135:647-654. doi:10.1017/S0031182008004198

M'rad S, Oudni-M'rad M, Filisetti D, Mekki M, Nouri A, Sayadi T et al (2010) Molecular identification of Echinococcus granulosus in Tunisia: first record of the buffalo strain (G3) in human and bovine in the country. The Open Veterinary Science Journal 4:27-30. doi:10.2174/1874318801004010027

Mutwiri T, Magambo J, Zeyhle E, Mkoji GM, Wamae CN, Mulinge E et al (2013) Molecular characterization of Echinococcus granulosus species/strains in human infections from Turkana/Kenya. East Afr Med J 90:235-240

Nakao M, McManus DP, Schantz PM, Craig PS, Ito A (2007) A molecular phylogeny of the genus Echinococcus inferred from complete mitochondrial genomes. Parasitology 134:713-722. doi:10.1017/S0031182006001934

Nakao M, Lavikainen A, Yanagida T, Ito A (2013) Phylogenetic systematics of the genus Echinococcus (Cestoda: Taeniidae). Int J Parasitol 43:1017-1029. doi:10.1016/j.ijpara.2013.06.002

Nakao M, Lavikainen A, Hoberg E (2015) Is Echinococcus intermedius a valid species? Trends Parasitol 31:342-343. doi:10.1016/j. pt.2015.04.012

Pawlowski ZS, Eckert J, Vuitton DA, Ammann RW, Kern P, Craig PS, Dar KF, De Rosa F, Filice C, Gottstein B et al (2001) Echinococcosis in humans: clinical aspects, diagnosis and treatment. In: Eckert $\mathrm{J}$, Gemmell MA, Meslin FX, Pawłowski ZS (eds) WHO/OIE manual on echinococcosis in humans and animals: a public health problem of global concern. World organisation for animal health (office international des epizooties) and World Health Organization. WHO, Paris, pp 32-34

Pednekar RP, Gatne ML, Thompson RCA, Traub RJ (2009) Molecular and morphological characterisation of Echinococcus from food producing animals in India. Vet Parasitol 165:58-65. doi:10.1016/j. vetpar.2009.06.021

Pezeshki A, Akhlaghi L, Sharbatkhori M, Razmjou E, Oormazdi H, Mohebali M et al (2013) Genotyping of Echinococcus granulosus from domestic animals and humans from Ardabil Province, Northwest Iran. J Helminthol 87:387-391. doi:10.1017/S0022149 X1200051X

Piccoli L, Bazzocchi C, Brunetti E, Mihailescu P, Bandi C, Mastalier B et al (2013) Molecular characterization of Echinococcus granulosus in South-Eastern Romania: evidence of G1-G3 and G6-G10 complexes in humans. Clin Microbiol Infect 19:578-582. doi:10.1111/j.14690691.2012.03993.x

Rainova I, Marinova I, Harizanov R, Jordanova D, Kaftandjiev I, Bikov I et al (2014) Parasitic diseases in Bulgaria in 2012. Problems of Infectious and Parasitic Diseases 42:29-38

Romig T, Ebi D, Wassermann M (2015) Taxonomy and molecular epidemiology of Echinococcus granulosus sensu lato. Vet Parasitol 213:76-84. doi:10.1016/j.vetpar.2015.07.035

Rozas J, Rozas R (1995) DnaSP, DNA sequence polymorphism: an interactive program for estimating population genetics parameters from DNA sequence data. Comput Appl Biosci 11:621-625

Saarma U, Jõgisalu I, Moks E, Varcasia A, Lavikainen A, Oksanen A et al (2009) A novel phylogeny for the genus Echinococcus, based on nuclear data, challenges relationships based on mitochondrial evidence. Parasitology 136:317-328. doi:10.1017/S0031182008005453

Sadjjadi SM, Mikaeili F, Karamian M, Maraghi S, Sadjjadi FS, ShariatTorbaghan S et al (2013) Evidence that the Echinococcus granulosus G6 genotype has an affinity for the brain in humans. Int J Parasitol 43:875-877. doi:10.1016/j.ijpara.2013.06.008

Saitou N, Nei M (1987) The neighbor-joining method: a new method for reconstructing phylogenetic trees. Mol Biol Evol 4:406-425

Scott JC, Stefaniak J, Pawlowski ZS, McManus DP (1997) Molecular genetic analysis of human cystic hydatid cases from Poland: 
identification of a new genotypic group (G9) of Echinococcus granulosus. Parasitology 114:37-43

Schneider R, Gollackner B, Schindl M, Tucek G, Auer H (2010) Echinococcus canadensis G7 (pig strain): an underestimated cause of cystic echinococcosis in Austria. AmJTrop Med Hyg 82:871874. doi:10.4269/ajtmh.2010.09-0639

Sharbatkhori M, Fasihi Harandi M, Mirhendi H, Hajialilo E, Kia EB (2011) Sequence analysis of cox 1 and nad 1 genes in Echinococcus granulosus G3 genotype in camels (Camelus dromedarius) from Central Iran. Parasitol Res 108:521-527. doi:10.1007/s00436-010-2092-7

Sharma M, Sehgal R, Fomda BA, Malhotra A, Malla N (2013a) Molecular characterization of Echinococcus granulosus cysts in north Indian patients: identification of G1, G3, G5 and G6 genotypes. PLoS Neg1 Trop Dis 7:e2262. doi:10.1371/journal. pntd. 0002262

Sharma M, Fomda BA, Mazta S, Sehgal R, Singh BB, Malla N (2013b) Genetic diversity and population genetic structure analysis of Echinococcus granulosus sensu stricto complex based on mitochondrial DNA signature. PLoS One 8:e82904. doi:10.1371/journal. pone.0082904

Simsek S, Kaplan M, Ozercan IH (2011) A comprehensive molecular survey of Echinococcus granulosus in formalin-fixed paraffin-embedded tissues in human isolates in Turkey. Parasitol Res 109:411416. doi:10.1007/s00436-011-2269-8

Šnábel V, Miterpáková M, D’Amelio S, Busi M, Bartková D, Turčeková L et al (2006) Genetic structuring and differentiation of Echinococcus multilocularis in Slovakia assessed by sequencing and isoenzyme studies. Helminthologia 43:196-202. doi:10.2478/s11687-006-0037-6

Šnábel V, Altintas N, D’Amelio S, Nakao M, Romig T, Yolasigmaz A et al (2009) Cystic echinococcosis in Turkey: genetic variability and first record of the pig strain (G7) in the country. Parasitol Res 105: 145-154. doi:10.1007/s00436-009-1376-2

Tamura K, Stecher G, Peterson D, Filipski A, Kumar S (2013) MEGA6: molecular evolutionary genetics analysis version 6.0. Mol Biol Evol 30:2725-2729. doi:10.1093/molbev/mst197
Thompson RCA, McManus DP (2002) Towards a taxonomic revision of the genus Echinococcus. Trends Parasitol 18:452-457

Thompson RCA, Boxell AC, Ralston BJ, Constantine CC, Hobbs RP, Shury $\mathrm{T}$ et al (2006) Molecular and morphological characterization of Echinococcus in cervids from North America. Parasitology 132: 439-447. doi:10.1017/S0031182005009170

Thompson RCA (2008) The taxonomy, phylogeny and transmission of Echinococcus. Exp Parasitol 119:439-446. doi:10.1016/j. exppara.2008.04.016

Yan, N., Nie HM, Jiang ZR, Yang AG, Deng SJ, Guo L, Yu H, Yan YB, Tsering D, Kong WS, Wang N, Wang JH, Xie Y, Fu Y, Yang DY, Wang SX, Gu XB, Peng XR, Yang GY (2016) Genetic variability of Echinococcus granulosus from the Tibetan plateau inferred by mitochondrial DNA sequences. http://www.sciencedirect. com/science/article/pii/S0304401713001222

Varcasia A, Canu S, Kogkos A, Pipia AP, Scala A, Garippa G et al (2007) Molecular characterization of Echinococcus granulosus in sheep and goats of Peloponnesus, Greece. Parasitol Res 101:1135-1139. doi:10.1007/s00436-007-0568-x

Wang J, Wang N, Hu D, Zhong X, Wang S, Gu X et al (2014) Genetic diversity of Echinococcus granulosus in Southwest China determined by the mitochondrial NADH dehydrogenase subunit 2 gene. ScientificWorldJournal 2014:867839. doi:10.1155/2014/867839

Wang N, Wang J, Hu D, Zhong X, Jiang Z, Yang A et al (2015) Genetic variability of Echinococcus granulosus based on the mitochondrial 16S ribosomal RNA gene. Mitochondrial DNA 26:396-401. doi:10.3109/19401736.2013.840590

Zait H, Kouidri M, Grenouillet FE, Umhang G, Millon L, Hamrioui B et al (2016) Molecular characterization of Echinococcus granulosus sensu stricto and Echinococcus canadensis in humans and livestock from Algeria. Parasitol Res 115:2423-2431. doi:10.1007/s00436-016-4994-5

Zhang T, Yang D, Zeng Z, Zhao W, Liu A, Piao D et al (2014) Genetic characterization of human-derived hydatid cysts of Echinococcus granulosus sensu lato in Heilongjiang Province and the first report of G7 genotype of E. canadensis in humans in China. PLoS One 9: e109059. doi:10.1371/journal.pone.0109059 